Article

\title{
Antifungal Starch-Gellan Edible Coatings with Thyme Essential Oil for the Postharvest Preservation of Apple and Persimmon
}

\author{
Mayra Sapper ${ }^{1 * *(\mathbb{D}}$, Lluís Palou ${ }^{2} \mathbb{D}$, María B. Pérez-Gago ${ }^{2} \mathbb{D}$ and Amparo Chiralt ${ }^{1}$ \\ 1 Instituto Universitario de Ingeniería de Alimentos para el Desarrollo, Universitat Politècnica de València, \\ Camino de Vera s/n, 46022 Valencia, Spain; dchiralt@tal.upv.es \\ 2 Centro de Tecnología Poscosecha (CTP), Instituto Valenciano de Investigaciones Agrarias (IVIA), \\ 46113 Moncada, Valencia, Spain; palou_llu@gva.es (L.P.); perez_mbe@gva.es (M.B.P.-G.) \\ * Correspondence: maysap@etsiamn.upv.es; Tel.: +34-644-323-055
}

Received: 9 May 2019; Accepted: 21 May 2019; Published: 24 May 2019

\begin{abstract}
Starch-gellan (80:20) coating formulations were applied to apples and persimmons to analyse their effectiveness controlling the weight loss, respiration rate, fruit firmness, and fungal decay during postharvest. Thyme essential oil (EO) was incorporated ( 0.25 and $0.5 \mathrm{~g}$ per g of polymer) directly or encapsulated in lecithin to enhance antifungal action. Coatings did not reduce weight loss or firmness changes in apples, but they prevented water loss in persimmons. In contrast, no significant effect of the coatings was observed on the respiration rates and the respiration quotient of persimmons, whereas the respiration rates and quotient was increased in apples. On the other hand, the coatings without lecithin reduced the incidence and severity of black spot caused by Alternaria alternata in persimmons, regardless of the content of essential oil. Likewise, these reduced the severity of gray mold caused by Botrytis cinerea in apples. No positive effect of lecithin in coatings was observed on the postharvest quality and decay in either apples or persimmons, nor did EO exert antifungal action despite its proven effectiveness in in vitro tests.
\end{abstract}

Keywords: cassava starch; gellan; thyme essential oil; antifungal edible coatings; postharvest; fruit

\section{Introduction}

Postharvest diseases are one of the major factors that affect the quality of horticultural fresh products during storage. Since fruit and vegetables are living organisms, their shelf life is greatly affected by temperature, relative humidity (RH), composition of the atmosphere during and after harvest, and the type and degree of infection by microorganisms or attack by insects [1]. Fruit contains high levels of sugars and nutrient elements, and the low $\mathrm{pH}$ values make them particularly susceptible to fungal decay. Fruit fungal infection may occur during flowering, fruit growth, harvesting, transport, packing operations, postharvest storage, or after purchase by the consumer [2]. Moreover, the natural resistance of fruit and vegetables to disease declines with storage duration and ripeness [3].

Gray mold caused by Botrytis cinerea Pers. is considered one of the most serious and common postharvest diseases of various fruit, including apples and persimmons [4,5]. The infection may occur in the field, from bloom to harvest, or after harvest, typically causing nests of decay. In fruit that are often stored for extended periods such as apples, field infections that remained latent can resume growth during storage, when the pathogen takes advantage of fruit maturity and environmental conditions and the disease develops (low temperatures and high humidity). In this sense, B. cinerea is very well adapted to low temperatures, and it is even able to grow at $0{ }^{\circ} \mathrm{C}$ [6]. Infection starts with a darker circular area where the fruit tissues are softer than the other fruit parts, and subsequent 
abundant sporification, whose colour ranges from white to gray, can develop from the site of infection in conditions of ambient temperature and high humidity [7]. Alternaria alternata (Fr.) Keissl. is the causal agent of postharvest black spot in persimmons (Diospyros kaki Thunb.) [8], and is generally considered a weak and opportunistic pathogen that gains entry into the fruit via wounds or natural openings, and remains quiescent until the fruit ripens [9]. A. alternata and Penicillium spp. were found to be the main causal agents of latent and wound infections in persimmons in Spain [5].

After harvest, fresh produce also suffer physiological and biochemical changes that cause detrimental changes in quality and shelf life. Respiration, transpiration, and ethylene production are the main factors contributing to the deterioration of fruits and vegetables [10]. Ethylene is a hormone produced by climacteric fruits, or when fruit undergoes stress, and is partially responsible for changes in the flavour, colour, and texture of fruits and vegetables. In addition, fresh fruits and vegetables lose water during storage due to respiratory and transpiration processes [11]. Water stress also causes metabolic alterations and changes in enzyme activation, causing accelerated senescence, a decline in nutritional value, and increased susceptibility to chilling injury and pathogen invasion. Respiration consists of the oxidative breakdown of organic reserves to simpler molecules, including carbon dioxide $\left(\mathrm{CO}_{2}\right)$ and water, with the release of energy [12]. All these biological factors, such as respiration, ethylene production, and resistance to water diffusion depend on the fruit commodity and cultivar, physiological stage at harvest, and storage conditions, which are also related to the composition of the surface waxes. Thus, for example, Morice and Shorland [13] reported that hydrocarbons, alcohols, fatty acids, ursolic acid, and $\alpha$-farnesene are the main components in natural apple surface waxes, and the amount and composition of these components changed during storage depending on the apple cultivar.

In the last decade, considerable research has been carried out into the development of edible coatings aiming to control the physiological activity of fruit. These coatings can modify the internal gas composition and reduce the water loss through the regulation of oxygen $\left(\mathrm{O}_{2}\right), \mathrm{CO}_{2}$, and water vapour exchange between the fruit and the surrounding atmosphere. However, a certain degree of $\mathrm{O}_{2}$ and $\mathrm{CO}_{2}$ permeability is necessary to avoid anaerobic respiration, which induces ethanol production, off-flavour formation, and the loss of produce quality [10]. An additional advantage of edible coatings is the possibility of incorporating food-grade ingredients, such as antimicrobial agents, antioxidants, flavours, colour pigments, and vitamins into the basic formulation with the aim of improving their functional properties.

Traditionally, the postharvest disease control of fresh fruits and vegetables involves the use of synthetic chemical fungicides in those products for which their use is legislated. However, new restrictive regulations regarding fungicide residues, the reduction of the legal acceptability limits of specific fungicides, the emergence of fungicide-resistant strains of the pathogens, and an increasing public concern towards these compounds have led to a global increase in the need to seek safer postharvest alternatives to control the decay of fruits and vegetables [14]. Some of these include antimicrobial antagonists (bacteria, yeast, and fungi) that perform as biocontrol agents, synthetic and natural antimicrobials classified as food-grade additives, or generally recognized as safe (GRAS) compounds, such as organic and inorganic acids and their salts, chitosan, essential oils (EOs), or other plant extracts and different physical methods. Among the natural compounds, EOs and their components have been reported to suppress fungal growth, both in in vitro and in vivo studies. Thus, for example, tea tree, palmarosa and star anise EO vapours completely inhibited the in vitro germination of the apple pathogen Penicillium expansum L. [15]; Melissa officinalis EO was effective against B. cinerea, P. expansum, and Rhizopus stolonifer (Ehrenb.) Vuill. in in vitro studies [16]. Pulicaria mauritanica EO was effective against Alternaria sp., P. expansum, and R. stolonifer [17]. In in vivo studies, the addition of lemon EO enhanced the antifungal activity of chitosan against $B$. cinerea in strawberries [18]; garlic extracts and clove EO treatments reduced the postharvest decay caused by B. cinerea and P. expansum when applied directly to apples [19]; and a chitosan-oregano EO emulsion exhibited an inhibitory effect on pomegranate fruit inoculated with Botrytis sp., but caused some 
phytotoxicity [20]. Usually, the antibacterial effect of EOs relies on their high content of terpenes and terpenoids and also on the content of other aromatic and aliphatic constituents, all of which are characterized by low molecular weight [21].

However, in spite of the great potential of EOs, the main limitation to their application for decay control is the possible induction of a strong odour or flavour in fruit, phytotoxicity risks, and technological issues associated with commercial-scale fumigations or liquid applications [22]. The addition of EOs to edible coatings based on polymeric matrices could render them more effective at prolonging the postharvest life of horticultural produce, slowing down the diffusion rate of the antimicrobial agent and maintaining a higher concentration of the active compound on the fruit surface for a longer period, while preventing phytotoxicity by avoiding the direct contact of the EO with the fruit skin through the encapsulating action of the polymer. Additionally, fruit coatings can delay or retard the ripening process in climacteric fruit by modifying their internal gas composition and changing their permeability to $\mathrm{O}_{2}, \mathrm{CO}_{2}$, and ethylene production [23]. Among the different EOs, thyme EO exhibited antifungal action against $B$. cinerea and A. alternata when included in starch-gellan films in in vitro studies [24], as well as a complete growth inhibition of $B$. cinerea as vapour in in vitro tests [25]. Gellan, a microbial gum consisting of repeating tetrasaccharide units of glucose, glucuronic acid, and rhamnose residues joined in a linear chain, forms starch-gellan composite films with improved mechanical and barrier properties [24], which could be effective at preserving fruit quality during postharvest storage when applied as coatings. Furthermore, given the antifungal effect of these films when these contained thyme essential oil [24], their application as fruit coatings could represent a good strategy to extend the fruit postharvest life in terms of both quality maintenance and fungal growth inhibition. Nevertheless, in vivo assays in different fruits must be carried out in order to validate the beneficial effect of these coatings.

In this study, starch-gellan coatings incorporating thyme (Thymus zygis Loefl. ex L.) EO were applied to apples and persimmons to evaluate: (1) the postharvest behaviour of coated fruit in terms of weight loss, respiration rates, and mechanical properties, and (2) the antifungal efficacy of these coatings applied as a curative treatment against B. cinerea in apple and A. alternata in persimmon.

\section{Materials and Methods}

\subsection{Reagents}

To prepare the coating-forming systems (CFS), cassava starch (S) (with 10\% amylose content) (Quimidroga S.A., Barcelona, Spain), low acyl gellan gum (G) (KELCOGEL F, Premium Ingredients, Murcia, Spain), non-GMO soy lecithin with 45\% phosphatidylcholine (L) (Lipoid P45, Lipoid GmbH, Ludwigshafen, Germany) and thyme (T. zygis) essential oil (Plantis, Artesanía Agrícola SA, Barcelona, Spain) (EO) were used. The glycerol used as plasticizer was supplied by Panreac Química S.A. (Castellar de Vallès, Barcelona, Spain) and the polyoxyethylenesorbitan trioleate (Tween $85^{\circledR}$ ) (T) was purchased from Sigma-Aldrich (Madrid, Spain).

\subsection{Preparation of CFS}

The formulations were prepared using $S$ and $G$ in a ratio of 8:2, with glycerol as the plasticiser $(0.25 \mathrm{~g}$ per $\mathrm{g}$ of polymer), on the basis of previous studies [26,27]. Firstly, $\mathrm{S}$ was dispersed in distilled water and kept at $95^{\circ} \mathrm{C}$ for $30 \mathrm{~min}$ to induce complete starch gelatinization. Meanwhile, G solution was obtained under stirring at $90^{\circ} \mathrm{C}$ for $60 \mathrm{~min}$. Both solutions were cooled down and afterwards, glycerol was added. The $\mathrm{S}$ and $\mathrm{G}$ systems were mixed to obtain the solutions without $\mathrm{EO}$. The thyme $\mathrm{EO}(0.25 \mathrm{~g}$ per $\mathrm{g}$ and $0.5 \mathrm{~g}$ per $\mathrm{g}$ of polymer), which was used as an antifungal agent, was incorporated, either by direct emulsification or encapsulated in lecithin liposomes (polymer: lecithin ratio of 1:0.5). In the first case, the EO was added directly and the dispersions were homogenized for $3 \mathrm{~min}$ at $13.500 \mathrm{rpm}$ using a rotor-stator homogenizer (Ultraturrax Yellow Line DL 25 Basic, IKA, Staufen, Germany). In the second case, the liposome dispersions were previously prepared and added directly to the initial 
polymer blend solution and kept under soft magnetic stirring for $2 \mathrm{~h}$. A formulation was also obtained with lecithin liposomes without EO, as a control. To obtain the lecithin dispersions, lecithin $\left(5 \%, \mathrm{w} \cdot \mathrm{w}^{-1}\right)$ was dispersed in distilled water and stirred for at least $4 \mathrm{~h}$ at $700 \mathrm{rpm}$. The EO $\left(2.5 \%\right.$ and $\left.5 \% \mathrm{w} \cdot \mathrm{w}^{-1}\right)$ was added to the lecithin dispersion by using a sonicator (Vibra Cell, Sonics and Materials, Inc., Newtown, CT, USA) at $20 \mathrm{kHz}$ for $10 \mathrm{~min}$ with pulses of $1 \mathrm{~s}$, as described by Valencia-Sullca et al. [28]. Tween 85 was also added to S:G CFS $\left(10^{5} \mathrm{mg} \cdot \mathrm{L}^{-1}\right)$ in order to ensure the complete wettability of the fruit surface, according to a previous study [29], and tested on apples in a preliminary test. All the solutions were degassed using a vacuum pump (MZ 2C NT, Vacuubrand GmbH + CO KG, Germany). A total of six formulations were obtained: starch:gellan (S:G), control with lecithin (S:G-L), formulations with EO, non-encapsulated (S:G-0.25 and S:G-0.5), and lecithin-encapsulated (S:G-0.25-L and S:G-0.5-L).

\subsection{Rheological Behaviour and Contact Angle of the CFS}

The rheological behaviour was analysed in triplicate at $25^{\circ} \mathrm{C}$ by means of a rotational rheometer (HAAKE Rheostress 1, Thermo Electric Corporation, Karlsruhe, Germany) by using a sensor system of coaxial cylinders, type Z34DIN Ti. Measurements were taken between 0-100 s ${ }^{-1}$. The obtained data was fitted to the Ostwald de Waale power law model (Equation (1)) in order to determine the consistency $(K)$ and the flow behaviour indices $(n)$ :

$$
\sigma=K \cdot\left(\frac{\partial u}{\partial y}\right)^{n}
$$

where $\sigma=$ shear stress $(\mathrm{Pa}), K=$ flow consistency index $\left(\mathrm{Pa} \cdot \mathrm{s}^{n}\right), \frac{\partial_{u}}{\partial_{y}}=$ shear rate $\left(\mathrm{s}^{-1}\right)$, and $n=$ the flow behaviour index.

The contact angle $(\theta)$ was determined by means of a Dynamic Contact Angle measuring device and Tensiometer (OCA 20, DataPhysics Instruments GmbH, Filderstadt, Germany). For this purpose, thin sections of the skin of the fruit were cut and placed on a glass plate to proceed with the measurements. Then, a droplet of each formulation was placed on the horizontal surface with a needle of $1.19 \mathrm{~mm}$ in internal diameter, and the contact angle at the fruit surfaces was measured by the sessile drop method [30]. Measurements were taken in less than $10 \mathrm{~s}$. Image analyses were carried out using SCA20 software. At least 12 replicates were obtained.

\subsection{Quality of Coated Fruit}

Apples (Malus domestica Borkh cv. Golden Delicious) and persimmons (Diospyros kaki Thunb. cv. Rojo Brillante) were purchased from local packinghouses (Valencia, Spain) before any postharvest treatments were applied. Fruit were chosen according to their uniform shape, size, colour, and the absence of surface defects; then, they were subsequently cleaned and disinfected by a 4-min immersion in a $1 \%$ sodium hypochlorite solution, thoroughly rinsed with tap water, and air-dried at room temperature before coating application.

CFS were applied manually, using approximately $1.5 \mathrm{~mL} /$ fruit, and spread evenly over the fruit surface by using latex glove hands, following the method described by Bai et al. [31]. Water was applied to control fruit to simulate the coating application and its possible effect on the inoculum. Then, each fruit was inspected to assure complete coverage, and all fruit were stored at $25^{\circ} \mathrm{C}$ and $65 \%$ $\mathrm{RH}$, for 14 days. Ten fruit were considered in each series (coated and non-coated fruits).

\subsubsection{Surface Density of Solids (SDS)}

The SDS was determined by weighing the samples with a precision balance (Kern PFB 120-3, Germany) before and after coating application to obtain the CFS adhered mass. To calculate the total 
adhered solids, the mass fraction of each CFS was considered and the SDS $\left(\mathrm{g} \cdot \mathrm{m}^{-2}\right)$ was estimated applying Equation (2), according to Marín et al. [32]:

$$
S D S=\frac{\left(m_{C}-m_{0}\right) \cdot X_{S \mathrm{CFS}}}{m_{0}} \cdot \rho \cdot \frac{1}{S_{e}}
$$

where $m_{C}=$ mass of the coated apple, $m_{0}=$ mass of the uncoated apple, $X_{s \text { CFS }}=$ mass fraction of the solids of the CFS (g solids per $\mathrm{g}$ of solution), $\rho=$ apple density $\left(\mathrm{g} \cdot \mathrm{cm}^{-3}\right)$. To obtain the specific surface $\left(S_{e}=6 / \mathrm{d}, \mathrm{m}^{2}\right.$ particles per $\mathrm{m}^{3}$ fruit), the average diameter $(\mathrm{d})$ was calculated considering a spherical geometry for the fruit.

\subsubsection{Weight Loss}

The weight loss of the fruit during storage was measured using an analytical balance (ME235P, Sartorius, Germany) before and after three, seven, and 14 days of storage. The mass loss was referred to the initial mass of the fruit, and the results were expressed as a relative mass loss rate $\left(\right.$ day $\left.^{-1}\right)$, which was obtained from the slope of the fitted straight line to the relative weight loss versus time data. Ten fruits were considered for each formulation and for control fruit.

\subsubsection{Respiration Rates}

Measurements were taken using a closed system, following the method proposed by Castelló et al. [33], with some modifications. Two apples were placed in hermetic glass jars with a septum in the lid for sampling headspace gas at different times. Gas sampling was carried out every $30 \mathrm{~min}$ for $4 \mathrm{~h}$ by means of a needle connected to a gas analyser (CheckMate 9900 PBI Dansensor, Ringsted, Denmark). Three replicates per treatment were performed after 7 and 14 days of storage. The respiration rate $\left(R_{i}\right)$ of the samples in terms of $\mathrm{CO}_{2}$ generation and $\mathrm{O}_{2}$ consumption was determined from the slope of the fitted linear equation, according to Equation (3). The respiration quotient (RQ) has been determined as the ratio between $\mathrm{CO}_{2}$ production and the $\mathrm{O}_{2}$ consumption.

$$
y_{i t}=y_{i 0} \pm 100 \cdot R_{i} \cdot \frac{M}{V} \cdot t
$$

where $y_{i t}=$ gas concentration $\left(\% \mathrm{O}_{2}, \% \mathrm{CO}_{2}\right)$ at time $t, y_{i 0}=$ initial gas concentration, $R_{i}=$ respiration rate $\left(\mathrm{mL} \cdot \mathrm{kg}^{-1} \cdot \mathrm{h}^{-1}\right), M=$ mass of the samples, $V=$ volume $(\mathrm{mL})$ of headspace, and $t=$ time.

\subsubsection{Fruit Firmness}

The firmness was measured using a Texture Analyser (Stable Micro Systems, TA.XT plus, Haslemere, England) fitted with an 11-mm diameter probe, applying a modification of the method described by Saei et al. [34]. A small skin area was removed from four opposite sides of each fruit around the equator. The probe penetrated the flesh at $10 \mathrm{~mm} \mathrm{~min}^{-1}$ and the maximum force $\left(F_{\max }, \mathrm{N}\right)$ required to break the flesh was used as fruit firmness. The distance at maximum force $\left(d_{\max }, \mathrm{mm}\right)$ was also taken as another representative parameter of the puncture curve. Ten replicates were used for each formulation after 14 days of storage. The same procedure was applied to uncoated fruit (control), both at the beginning and after 14 days of storage.

\subsection{In Vivo Antifungal Assays}

For the in vivo assays, B. cinerea strain BC03 from the IRTA Culture Collection (Lleida, Catalonia, Spain) was originally isolated from infected grapes from a vineyard located in Lleida and it was deposited at the Spanish Type Culture Collection (CECT-20973) at the University of Valencia (Burjassot, Valencia, Spain). A. alternata strain QAV-6 had been isolated from decayed persimmon fruit and maintained in the IVIA CTP Culture Collection of postharvest pathogens (Moncada, Valencia, Spain). These fungal strains were cultured on potato dextrose agar (PDA; Scharlab, Barcelona, Catalonia, 
Spain) petri dishes at $25^{\circ} \mathrm{C}$ in the dark and used after 7 to 14 days of active growth. Conidia were scraped from the cultures using a sterile loop and subsequently filtered and transferred to test tubes

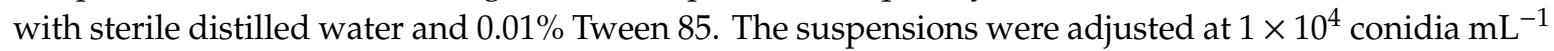
for $B$. cinerea and $5 \times 10^{5}$ conidia $\mathrm{mL}^{-1}$ for $A$. alternata, which were selected according to previous experience with these postharvest pathosystems $[5,19]$. The concentration of conidial suspensions was determined using a haemocytometer.

Fruit were wounded (approximately $1.6 \mathrm{~mm}$ in diameter and $2 \mathrm{~mm}$ deep) using the tip of a stainless-steel rod once in the fruit equator in the case of apples, and twice in the equator on the same side of the fruit in the case of persimmons (wounds located midway between the calyx and the stem end and 5-6 cm apart). Each wound was inoculated using a micropipette with $20 \mu \mathrm{L}$ of the correspondent spore suspension $24 \mathrm{~h}$ before the application of the coatings (assessment of the coatings' curative activity). As previously described, coatings were applied manually at approximately $1.5 \mathrm{~mL}$ per fruit. Air surface drying was allowed at room temperature, and fruit were subsequently placed in perforated plastic trays avoiding direct contact between fruit and incubated at $20^{\circ} \mathrm{C}$ and $85 \pm$ $5 \%$ RH. Twenty fruit-four replications of five fruit each-were used per treatment. Control fruit were inoculated and treated with water using the same procedure as that for coating application. Lesion diameters (disease severity, $\mathrm{mm}$ ) were measured after 7 and 12 days of incubation. Disease incidence (\%) was expressed as the percentage of infected wounds out of the total number of inoculated wounds per replicate and treatment [6].

\subsection{Statistical Analysis}

The statistical analyses of the results were performed through an analysis of variance (ANOVA) using Statgraphics Centurion XVI.II (StatPoint Technologies Inc., Warrenton, VA, USA). Fisher's least significant difference (LSD) test was used at the $95 \%$ confidence level to determine specific differences between means. Multifactor ANOVA was also used to analyse the effect of the different factors (storage time and type of coating).

\section{Results and Discussion}

\subsection{CFS Properties}

The viscosity and contact angle of the different CFS on apple and persimmon skin were analysed since these parameters can affect the coating retention/adhesion on the fruit surface after the coating treatment through their influence on the CFS gravitational drainage before drying and liquid spreadability, all of which affect the coating thickness and homogeneity. The flow curves of the CFS were fitted to the power law model and the rheological parameters (consistency index: $K$ and flow index: $n$ ), including the apparent viscosity $(\eta)$ at $100 \mathrm{~s}^{-1}$, are shown in Table 1. Pseudoplastic behaviour, with similar values of $n$-lower than 1 -was observed in all the cases. Apparent viscosities ranged between 25-42 $\mathrm{mPa} \cdot \mathrm{s}$, depending on the CFS composition. Directly-emulsified EO caused an increase in the apparent viscosity of the CFS according to the EO ratio, while lecithin-encapsulated EO reduced the viscosity of the formulations, which is probably due to the smaller droplet size in the encapsulated system [28]. Thus, the S:G-0.5 sample was the most viscous formulation and showed the highest consistency index.

The contact angles of the different CFS on apple and persimmon skin are also shown in Table 1. Values lower than $90^{\circ}$ indicate surface wettability, and therefore greater extensibility of the coating on the fruit surface. For a given CFS, the contact angles on the persimmon skin were lower than on the apple skin, which indicates a better wettability of persimmon with these types of formulations. The values depended on the coating composition, with the highest contact angle corresponding to the S:G formulation in apples. This could imply problems for the extension of this coating on the apple surface. A previous study [29] reported that $10^{5} \mathrm{mg} \cdot \mathrm{L}^{-1}$ of Tween 85 must be added to ensure the S:G coating spreadability on the apple surface, whereas no surfactant was necessary to enhance the CFS 
spreadability when these contained emulsified or lecithin-encapsulated EO. Therefore, Tween 85 was added to the S:G formulation and tested in a preliminary trial with apples, in comparison with the CFS without Tween 85 , in order to analyse the effect of the surfactant on the fruit quality during storage, as discussed in the next section.

Table 1. Rheological parameters (flow behavior index, n; consistency index, K; apparent viscosity at $100 \mathrm{~s}^{-1}, \eta$ ) and contact angle $(\theta)$ of the coating forming solution (CFS) on the skin of 'Golden Delicious' apple and 'Rojo Brillante' persimmon. Mean values and standard deviations.

\begin{tabular}{|c|c|c|c|c|c|}
\hline \multirow{2}{*}{ CFS } & \multicolumn{3}{|c|}{ Rheological Behavior } & \multicolumn{2}{|c|}{ Contact Angle $(\theta)$} \\
\hline & $n$ & $\mathrm{~K}(\mathrm{mPa} \cdot \mathrm{s})^{n}$ & $\eta$ at $100 \mathrm{~s}^{-1}(\mathrm{mPa} \cdot \mathrm{s})$ & Apple & Persimmon \\
\hline $\mathrm{S}: \mathrm{G}$ & $0.854 \pm 0.001^{d}$ & $65.0 \pm 0.2^{\mathrm{a}}$ & $33.1 \pm 0.1^{\mathrm{c}}$ & $96 \pm 2^{\mathrm{e}}$ & $67 \pm 3^{c d}$ \\
\hline S:G-L & $0.74 \pm 0.01^{\mathrm{a}}$ & $114 \pm 3^{b}$ & $35.0 \pm 0.1^{d}$ & $85 \pm 3^{d}$ & $72 \pm 2^{\mathrm{e}}$ \\
\hline S:G-0.25 & $0.86 \pm 0.01^{\mathrm{d}}$ & $59 \pm 9^{a}$ & $31 \pm 3^{b}$ & $69 \pm 3^{a}$ & $65 \pm 3^{c}$ \\
\hline S:G-0.25-L & $0.815 \pm 0.001^{\mathrm{c}}$ & $59.7 \pm 0.5^{\mathrm{a}}$ & $25.5 \pm 0.3^{\mathrm{a}}$ & $73 \pm 2^{b}$ & $50 \pm 6^{a}$ \\
\hline S:G-0.5 & $0.766 \pm 0.004^{b}$ & $124 \pm 3^{c}$ & $42.2 \pm 0.2^{\mathrm{e}}$ & $77 \pm 2^{c}$ & $68 \pm 2^{d}$ \\
\hline S:G-0.5-L & $0.809 \pm 0.002^{c}$ & $60 \pm 1^{a}$ & $25.05 \pm 0.03^{a}$ & $74 \pm 2^{b}$ & $55 \pm 4^{b}$ \\
\hline
\end{tabular}

Different superscript letters within the same column indicate significant differences among CFS according to Fisher's least significant difference (LSD) test $(p<0.05)$.

\subsection{Effect of the Incorporation of Tween 85 into CFS on Apple Quality}

The incorporation of Tween 85 into the S:G CFS significantly decreased the contact angle on the apple surface (from $96 \pm 2$ to $47 \pm 3$ ) and increased the apparent viscosity (from $37.9 \pm 0.3$ to $187.8 \pm$ $0.1 \mathrm{mPa} \cdot \mathrm{s})$. As expected, both changes affected the retention/adhesion of the CFS on the apple surface, as shown in the values of SDS on the fruit, which ranged from $2.6 \pm 0.8$ to $3.4 \pm 0.5 \mathrm{~g} \cdot \mathrm{m}^{-2}$. Interactions of Tween 85 with the CFS components and with the fruit surface affected both the viscosity and the contact angle of the CFS. As described by Marín et al. [32], surfactant molecules form complexes, with the helical conformation of amylose favouring the chain aggregation and increasing the system viscosity. Likewise, this complex formation implies that a high amount of surfactant is required to enhance the spreading of the CFS on the fruit surface, as discussed by Sapper et al. [29]. The increase in the SDS values for the S:G formulation with Tween 85 can be attributed to the higher solid content of the formulation, the greater viscosity that limits liquid gravitational drainage, and the lower contact angle. However, given the amphiphilic nature of the surfactant, its interactions with the natural wax of the fruit cuticle could also modify the overall barrier properties of the wax-coating assembly on the fruit surface. As is known, cuticular waxes are the primary components of the cuticle that are responsible for its permeability and wettability. These waxes are embedded in the cutin and form a continuous layer on the top of the cutin [35]. It has been reported that the cuticular wax content in apple fruit increases during fruit development and storage [36].

Table 2 shows the relative weight loss rate, respiration rate, and puncture parameters of apples after 7 days of storage at $25^{\circ} \mathrm{C}$ for samples coated with the S:G formulation containing Tween 85 or not, in comparison with the uncoated control sample. Little differences in the relative weight loss rate were observed between the uncoated control sample and the one coated with the surfactant-free formulation. However, a significantly higher weight loss rate was observed for those coated with the formulation containing Tween 85. The coatings reduced the $\mathrm{O}_{2}$ consumption rate of the fruit, which can be attributed to the low $\mathrm{O}_{2}$ permeability of these films [24], but this reduction was particularly significant for the coating containing Tween 85 . The $\mathrm{CO}_{2}$ production rate was not significantly affected by the S:G coating compared to the control sample, but the coating containing Tween 85 significantly reduced this rate. As a consequence, the respiratory quotient was higher than 1 for both coated samples, indicating the creation of a modified atmosphere in the fruit and a shift towards anaerobic respiration pathways. The incorporation of Tween 85 resulted in a general decrease in the gas transfer rate and an increase in water transfer rate. As discussed above, the interactions of Tween 85 with the cuticular waxes, as well as its effect on the decrease in the cohesion forces of the S:G matrix (limiting of chain 
packing), could explain the changes observed in the gas and water vapour barrier properties of the coating and their effect on the fruit. These changes also had an effect on the fruit texture, as shown in Table 2. Although all the samples exhibited similar fruit firmness as deduced from the lack of significant differences among treatments regarding the maximum puncture force, there were significant differences in the maximum penetration distance $\left(d_{\max }\right)$ at the tissue rupture. Fruits coated with the S:G formulation containing Tween 85 had significantly higher $d_{\max }$ values, which reflect changes in the tissue texture. This fact can be related to the greater loss of water, and therefore, cellular turgidity, which is associated with a more marked superficial dehydration of the fruit with this coating. This factor is considered one of the main causes of texture changes in fruit [37]. After 7 days of storage, all the samples had higher $d_{\max }$ than the fruit at the initial time, with those coated with the CFS containing Tween 85 being significantly more deformable. Therefore, the use of Tween in the S:G formulation to improve its wettability on the apple surface was discarded on the basis of the negative effects on the fruit weight loss and texture.

Table 2. Effect of the incorporation of Tween 85 into the cassava starch:low acyl gellan gum (S:G) coating formulation on the postharvest behavior and quality of coated 'Golden Delicious' apples: relative weight loss rate $\left(\mathrm{day}^{-1}\right)$, respiration rates (consumption of $\mathrm{O}_{2}$ and production of $\mathrm{CO}_{2}, \mathrm{~mL} \cdot \mathrm{kg}^{-1} \cdot \mathrm{h}^{-1}$ ), respiration quotient $(\mathrm{RQ})$, and values of the maximum puncture force $\left(F_{\max }, \mathrm{N}\right)$ and penetration distance $\left(d_{\max }, \mathrm{mm}\right)$ after 7 days of storage at $25^{\circ} \mathrm{C}$. Uncoated samples were used for values at harvest and the control after 7 days of storage.

\begin{tabular}{|c|c|c|c|c|}
\hline & Control & Control & S:G & S:G-Tween 85 \\
\hline & Initial Time & & 7 days & \\
\hline Weight loss rate & - & $0.36 \pm 0.02^{a}$ & $0.36 \pm 0.01^{a}$ & $0.66 \pm 0.06^{b}$ \\
\hline$F_{\max }$ & $43 \pm 7$ & $46 \pm 6^{a}$ & $49 \pm 8^{a}$ & $46 \pm 4^{\mathrm{a}}$ \\
\hline$d_{\max }$ & $3.0 \pm 0.3$ & $3.6 \pm 0.4^{\mathrm{a}}$ & $3.9 \pm 0.5^{\mathrm{a}}$ & $4.6 \pm 0.7^{\mathrm{b}}$ \\
\hline $\mathrm{RO}_{2}$ & $12.94 \pm 0.05$ & $12.9 \pm 1.3^{b}$ & $11.4 \pm 0.8^{b}$ & $7.77 \pm 0.02^{a}$ \\
\hline $\mathrm{RCO}_{2}$ & $13.9 \pm 0.6$ & $15.2 \pm 0.7^{b}$ & $18 \pm 1^{\mathrm{c}}$ & $11.0 \pm 0.2^{\mathrm{a}}$ \\
\hline RQ & $1.07 \pm 0.05$ & $1.18 \pm 0.07^{\mathrm{a}}$ & $1.58 \pm 0.03^{\mathrm{c}}$ & $1.41 \pm 0.03^{b}$ \\
\hline
\end{tabular}

Different superscript letters within the same row indicate significant differences among CFS according to Fisher's LSD test $(p<0.05)$.

\subsection{Effect of CFS on Postharvest Behaviour and Quality of Apples and Persimmons}

Table 3 shows the initial values of respiration rates and puncture parameters of apples and persimmons, and Table 4 shows the same parameters, together with the values of SDS, for coated and uncoated 'Golden Delicious' apples and 'Rojo Brillante' persimmons after storage at $25^{\circ} \mathrm{C}$. SDS values are indicators of the coating thickness on the fruit; the higher the SDS, the thicker the coating. The SDS value depends on the amount of CFS that adhered to the surface of the fruit and the total solid content of the formulation. The former, in turn, is affected by the wetting/spreading capacity and the viscosity of the coating formulations. In general, the SDS values were higher in apples than in persimmons, which could be related to differences in both the surface tension of the skin [29] and in the skin morphology of the fruit. Thus, persimmons are characterized by a smooth skin, where the lack of small superficial pores could limit the capillary retention of the liquid fraction. Similarly, the CFS composition slightly affected the SDS differently depending on the fruit. In apples, the presence of lecithin in the formulation significantly reduced the SDS, whereas smaller differences associated with the CFS composition were observed in persimmons, and these were seemingly more closely related to the solid content of the CFS (incorporation of EO and/or lecithin to the formulations). 
Table 3. Respiration rates (consumption of $\mathrm{O}_{2}$ and production of $\mathrm{CO}_{2}, \mathrm{~mL} \cdot \mathrm{kg}^{-1} \cdot \mathrm{h}^{-1}$ ), respiration quotient $(\mathrm{RQ})$, and maximum puncture force $\left(F_{\max }, \mathrm{N}\right)$ and penetration distance $\left(d_{\max }, \mathrm{mm}\right)$ of uncoated 'Golden Delicious' apples and 'Rojo Brillante' persimmons at initial time. Mean values and standard deviations.

\begin{tabular}{cccccc}
\hline & $\mathbf{R ~ O}_{\mathbf{2}}$ & $\mathbf{R ~ C O}_{\mathbf{2}}$ & $\mathbf{R Q}$ & $\boldsymbol{F}_{\max }$ & $\boldsymbol{d}_{\max }$ \\
\hline Apple & $13.7 \pm 1.5$ & $12.2 \pm 0.2$ & $0.9 \pm 0.1$ & $29 \pm 2$ & $2.2 \pm 0.1$ \\
Persimmon & $5.7 \pm 1.1$ & $5.4 \pm 0.9$ & $0.94 \pm 0.02$ & $21.1 \pm 0.5$ & $2.5 \pm 0.3$ \\
\hline
\end{tabular}

Table 4. Surface density of solids (SDS, $\mathrm{g} \cdot \mathrm{m}^{-2}$ ), weight loss rate $\left(\mathrm{day}^{-1}\right)$, respiration rates (consumption of $\mathrm{O}_{2}$ and production of $\left.\mathrm{CO}_{2}, \mathrm{~mL} \cdot \mathrm{kg}^{-1} \cdot \mathrm{h}^{-1}\right)$, respiration quotient $(\mathrm{RQ})$, maximum puncture force $\left(F_{\max }\right.$, $\mathrm{N})$, and penetration distance $\left(d_{\max }, \mathrm{mm}\right)$ of coated and uncoated 'Golden Delicious' apples and 'Rojo Brillante' persimmons for 7 or 14 days of storage at $25^{\circ} \mathrm{C}$.

\begin{tabular}{|c|c|c|c|c|c|c|c|}
\hline & Control & S:G & S:G-L & S:G-0.25 & S:G-0.25-L & S:G-0.5 & S:G-0.5-L \\
\hline SSD & - & $1.3 \pm 0.3^{c}$ & $0.8 \pm 0.1^{\mathrm{a}}$ & $1.4 \pm 0.3^{c}$ & $1.1 \pm 0.1^{b}$ & $1.5 \pm 0.2^{c}$ & $1.0 \pm 0.1^{b}$ \\
\hline $\mathrm{R} \mathrm{O}_{2}(7 \mathrm{~d})$ & $6.0 \pm 1.4^{\mathrm{ab}}$ & $6.0 \pm 1.5^{\mathrm{ab}}$ & $6.5 \pm 1.6^{\mathrm{ab}}$ & $6.6 \pm 0.8^{\mathrm{ab}}$ & $6.5 \pm 1.0^{\mathrm{ab}}$ & $7.6 \pm 0.6^{b}$ & $5.1 \pm 0.9^{\mathrm{a}}$ \\
\hline $\mathrm{RCO}_{2}(7 \mathrm{~d})$ & $6.5 \pm 1.2^{\mathrm{a}}$ & $7.8 \pm 0.8^{a b}$ & $8.4 \pm 2.0^{\mathrm{ab}}$ & $8.8 \pm 0.1^{a b}$ & $8.3 \pm 0.7^{a b}$ & $9.7 \pm 1.0^{b}$ & $6.8 \pm 0.9^{a}$ \\
\hline $\mathrm{RO}_{2}(14 \mathrm{~d})$ & $5.3 \pm 0.8^{\mathrm{a}}$ & $8.4 \pm 1.1^{\mathrm{d}}$ & $7.3 \pm 0.5^{\mathrm{cd}}$ & $7.0 \pm 0.1^{\mathrm{bcd}}$ & $5.9 \pm 0.8^{a b}$ & $6.5 \pm 0.9^{a b c}$ & $5.6 \pm 0.9^{a b}$ \\
\hline $\mathrm{RCO}_{2}(14 \mathrm{~d})$ & $6.2 \pm 1.3^{\mathrm{a}}$ & $10.4 \pm 1.1^{\mathrm{d}}$ & $9.0 \pm 0.9^{\mathrm{cd}}$ & $8.1 \pm 0.2 b c$ & $7.2 \pm 0.6^{a b}$ & $7.9 \pm 0.6^{b c}$ & $7.2 \pm 0.6^{\mathrm{ab}}$ \\
\hline $\mathrm{RQ}(14 \mathrm{~d})$ & $1.2 \pm 0.1^{\mathrm{a}}$ & $1.2 \pm 0.1^{\mathrm{a}}$ & $1.23 \pm 0.05^{\mathrm{a}}$ & $1.2 \pm 0.1^{\mathrm{a}}$ & $1.2 \pm 0.1^{\mathrm{a}}$ & $1.2 \pm 0.1^{\mathrm{a}}$ & $1.3 \pm 0.1^{\mathrm{a}}$ \\
\hline$F_{\max }(14 \mathrm{~d})$ & $27 \pm 2^{a b}$ & $31 \pm 3^{c}$ & $30 \pm 4$ bc & $29 \pm 3^{a b c}$ & $30.4 \pm 1.5^{b c}$ & $32 \pm 2^{c}$ & $26.1 \pm 1.2^{\mathrm{a}}$ \\
\hline$d_{\max }(14 \mathrm{~d})$ & $3 \pm 1^{\mathrm{a}}$ & $3 \pm 1^{\mathrm{a}}$ & $3 \pm 1^{\mathrm{a}}$ & $3 \pm 0^{\mathrm{a}}$ & $3 \pm 1^{\mathrm{a}}$ & $3 \pm 1^{a}$ & $3.4 \pm 0.5^{\mathrm{a}}$ \\
\hline $\mathrm{R} \mathrm{O}_{2}(7 \mathrm{~d})$ & $5.2 \pm 0.3^{\mathrm{a}}$ & $3.3 \pm 1.6^{\mathrm{a}}$ & $3.8 \pm 0.6^{\mathrm{a}}$ & $2.9 \pm 0.2^{\mathrm{a}}$ & $3.9 \pm 2.1^{\mathrm{a}}$ & $3.6 \pm 0.3^{a}$ & $4.1 \pm 1.7^{\mathrm{a}}$ \\
\hline $\mathrm{RCO}_{2}(7 \mathrm{~d})$ & $5.6 \pm 0.5^{\mathrm{a}}$ & $3.8 \pm 1.0^{\mathrm{a}}$ & $4.2 \pm 0.9^{\mathrm{a}}$ & $3.4 \pm 0.4^{\mathrm{a}}$ & $4.5 \pm 2.0^{\mathrm{a}}$ & $4.6 \pm 0.7^{\mathrm{a}}$ & $4.8 \pm 2.1^{\mathrm{a}}$ \\
\hline $\mathrm{RQ}(7 \mathrm{~d})$ & $1.08 \pm 0.04^{\mathrm{a}}$ & $1.2 \pm 0.3^{\mathrm{a}}$ & $1.11 \pm 0.05^{\mathrm{a}}$ & $1.19 \pm 0.03^{\mathrm{a}}$ & $1.3 \pm 0.3^{a}$ & $1.3 \pm 0.1^{\mathrm{a}}$ & $1.2 \pm 0.1^{\mathrm{a}}$ \\
\hline $\mathrm{R} \mathrm{O}_{2}(14 \mathrm{~d})$ & $3.7 \pm 0.6^{\mathrm{a}}$ & $4.2 \pm 1.8^{\mathrm{a}}$ & $3.0 \pm 1.1^{\mathrm{a}}$ & $3.3 \pm 0.4^{\mathrm{a}}$ & $2.2 \pm 0.2^{\mathrm{a}}$ & $2.6 \pm 0.6^{\mathrm{a}}$ & $3.5 \pm 1.9^{\mathrm{a}}$ \\
\hline $\mathrm{RCO}_{2}(14 \mathrm{~d})$ & $3.9 \pm 1.1^{\mathrm{a}}$ & $5.3 \pm 2.6^{\mathrm{a}}$ & $4.1 \pm 1.0^{\mathrm{a}}$ & $3.9 \pm 1.8^{\mathrm{a}}$ & $2.2 \pm 0.2^{\mathrm{a}}$ & $2.9 \pm 0.4^{\mathrm{a}}$ & $4.2 \pm 1.3^{\mathrm{a}}$ \\
\hline $\mathrm{RQ}(14 \mathrm{~d})$ & $1.0 \pm 0.1^{\mathrm{a}}$ & $1.3 \pm 0.1^{\mathrm{a}}$ & $1.4 \pm 0.2^{\mathrm{a}}$ & $1.2 \pm 0.4^{\mathrm{a}}$ & $1.0 \pm 0.0^{\mathrm{a}}$ & $1.1 \pm 0.1^{\mathrm{a}}$ & $1.3 \pm 0.3^{\mathrm{a}}$ \\
\hline$F_{\max }(14 \mathrm{~d})$ & $21 \pm 4^{\mathrm{a}}$ & $27 \pm 3^{b c}$ & $23 \pm 4^{\mathrm{ab}}$ & $27 \pm 5^{b c}$ & $28 \pm 6^{c}$ & $29 \pm 6^{c}$ & $28 \pm 6^{c}$ \\
\hline$d_{\max }(14 \mathrm{~d})$ & $5 \pm 1^{\mathrm{ab}}$ & $6 \pm 1^{b c}$ & $5 \pm 1^{\mathrm{a}}$ & $5 \pm 1^{\mathrm{a}}$ & $5.2 \pm 0.4^{\mathrm{abc}}$ & $6 \pm 1^{c}$ & $6 \pm 1^{b c}$ \\
\hline
\end{tabular}

Different superscript letters within the same row indicate significant differences among CFS according to Fisher's LSD test $(p<0.05)$.

The rate of relative weight loss after 14 days of storage was not significantly affected by coating application or composition, and ranged between $0.20-0.23 \mathrm{day}^{-1}$. In persimmons, water loss rates were higher than in apples and varied depending on the coating formulation. The highest values $\left(0.7 \mathrm{day}^{-1}\right)$ were obtained for uncoated samples, and those coated with CFS containing the highest content of lecithin-encapsulated EO (maximum lipid content in the film) and the lowest value $\left(0.52\right.$ day $\left.^{-1}\right)$ was obtained for samples coated with the formulation with emulsified EO (without lecithin) at the lowest ratio (minimum lipid content in the film). No significant differences were found between the other coating formulations and the control samples. These results indicate that persimmon fruits were more sensitive to dehydration than apples under these storage conditions, and the coatings with the lowest ratio of emulsified EO exerted a protective effect. As mentioned above, apples and persimmons are naturally covered by a continuous wax layer that provides the resistance to water movement across the cuticle. The differences in the water resistance of the untreated fruits can be attributed to the particular fruit physiology, skin morphology, and the composition of the natural waxes. The application of coatings containing hydrophobic compounds should improve the moisture resistance of the fruit, as an additional layer is deposited over the natural waxes. In the present study, none of the coatings reduced weight loss in apples, and only the coating that had the lowest amount of EO and no lecithin 
prevented water loss in persimmons. This might indicate a partial removal and/or modification of the natural waxes that are present on the peel of the fruits, resulting in no reduction in weight loss; so, further studies should be conducted in order to understand the effect of the EO and lecithin on the water barrier properties of coated apples and persimmons. Some other studies also reflected no effect of coatings based on biopolymers and lipids on the weight loss reduction of different fruits, such as apples [31], plums [38], table grapes [39], or cherry tomatoes [40], compared to uncoated fruits.

Table 4 also shows respiration rates of both fruit at 7 and 14 days of storage. In apples, a multifactor ANOVA (results not shown) did not reveal a significant effect of the storage time on respiration rates, although the coatings had a significant influence. In general, coatings tend to increase the $\mathrm{O}_{2}$ consumption and $\mathrm{CO}_{2}$ production rates with respect to the control sample, and only those containing lecithin-encapsulated EO showed no significant differences with respect to the control sample. The alterations in the respiration pathway affected the $R Q$, which indicates the nature of the substrate used during the respiration process. Thus, a RQ equal to 1.0 indicates that the metabolic substrates are carbohydrates, whereas an RQ higher than 1 indicates that the substrates are organic acids [41]. The multifactor ANOVA in RQ reveals a significant effect of storage time and coating formulation. RQ slightly increased at 14 days, and was higher in all the coated samples. This indicates that the metabolic substrates are shifting from carbohydrates to organic acids [41] more quickly in coated samples.

In contrast, coatings were observed to have no significant effect on the respiration rates of persimmons, which exhibited lower respiration rates than apples, with a respiration quotient of nearly 1 . Climacteric fruit, such as apples, exhibit a peak of respiration and ethylene $\left(\mathrm{C}_{2} \mathrm{H}_{4}\right)$ production associated with senescence or ripening [12], which could explain the observed differences.

The texture changes in fruits depend on both cell wall degradation and the loss of tissue turgidity [42]. Table 4 shows the values of the $F_{\max }$ and $d_{\max }$ for the different coated and uncoated fruits after 14 days of storage. No significant changes in the maximum puncture force (failure point) were observed for either uncoated or coated apples after storage with respect to the initial values before storage (Tables 3 and 4). However, although no significant differences were observed in terms of the maximum penetration distance between coated and control apples at the end of the storage, the values were slightly higher than before storage, which can be associated with a loss of cellular turgidity due to the superficial dehydration of the apples. The limited water vapor barrier capacity of these films [24] and their relative lack of thickness on the fruit mean that these are scarcely effective at controlling moisture transfer in apples.

In the case of persimmons, the coatings had a significant effect $(p<0.05)$, maintaining the firmness of the fruit. On the other hand, although there were no notable differences in terms of the maximum penetration distance at the failure point $(5-6 \mathrm{~mm})$ between coated and uncoated samples at the end of the storage, the values were significantly higher than the initial value $(2.5 \mathrm{~mm})$ before storage. This indicates changes in the texture of the tissue over time, which can be related to the progress in maturity and water loss. The $F_{\max }$ values increased from 21.1 up to $31 \mathrm{~N}$, which could be attributed to the greater deformability of the tissue allowing for deeper penetration without failure, thus accumulating more compressive and shear resistance [43]. The smallest changes occurred in the sample coated with CFS containing lecithin without EO.

The above results show that coatings have a different effect depending on whether the fruit is an apple or persimmon, which can be attributed to the different physiological patterns of the fruits and the specific interactions with the coatings. Although respiration patterns were slightly modified by coatings on apples with no effect on water loss, coatings exerted a better control of water loss in persimmon; however, these did not maintain the firmness mainly due to the progress of fruit ripening.

\subsection{Fungal Decay}

Table 5 shows the development of fungal decay on artificially inoculated 'Golden Delicious' apples and 'Rojo Brillante' persimmons. The applications of starch-gellan coatings did not significantly reduce the disease incidence on apples inoculated with B. cinerea, as compared to non-coated ones (control) 
after 7 or 12 days of storage at $20^{\circ} \mathrm{C}$. No effect of the addition of EO was observed, despite what had been observed in a prior in vitro study, where starch-gellan films with thyme EO exhibited a marked antifungal effect [24]. Nevertheless, all the coatings, regardless of their composition, significantly reduced the severity of gray mold with respect to the control samples (20-30\% reduction), with no particular observed effect of the antifungal EO.

Table 5. Mean values and standard deviations of disease incidence and severity of gray mold on 'Golden Delicious' apples artificially inoculated with Botrytis cinerea and black spot on 'Rojo Brillante' persimmons artificially inoculated with Alternaria alternata. Fruit were coated $24 \mathrm{~h}$ after fungal inoculation and incubated at $20^{\circ} \mathrm{C}$ and $85 \%$ RH for 7 and 12 days. Mean values of the reduction in disease incidence and severity are also shown.

\begin{tabular}{|c|c|c|c|c|c|c|c|c|}
\hline & \multicolumn{2}{|c|}{ Disease Incidence (\%) } & \multicolumn{2}{|c|}{$\begin{array}{l}\text { Reduction of } \\
\text { Incidence (\%) }\end{array}$} & \multicolumn{2}{|c|}{ Disease Severity (mm) } & \multicolumn{2}{|c|}{$\begin{array}{l}\text { Reduction of } \\
\text { Severity (\%) }\end{array}$} \\
\hline & 7 Days & 12 Days & 7 Days & 12 Days & 7 Days & 12 Days & 7 Days & 12 Days \\
\hline \multicolumn{9}{|c|}{ Apple gray mold } \\
\hline Control & $100 \pm 0^{a}$ & $100 \pm 0^{a}$ & - & - & $70 \pm 5^{b}$ & $100 \pm 5^{b}$ & - & - \\
\hline S:G & $75 \pm 25^{a}$ & $83 \pm 14^{a}$ & 25 & 17 & $44 \pm 5^{\mathrm{a}}$ & $74 \pm 13^{a}$ & 32 & 26 \\
\hline S:G-L & $92 \pm 14^{\mathrm{a}}$ & $92 \pm 14^{a}$ & 8 & 8 & $47 \pm 11^{\mathrm{a}}$ & $73 \pm 21^{a}$ & 27 & 27 \\
\hline S:G-0.25 & $75 \pm 25^{a}$ & $83 \pm 14^{a}$ & 25 & 17 & $53 \pm 8^{a b}$ & $76 \pm 15^{a}$ & 19 & 24 \\
\hline $\mathrm{S}: \mathrm{G}-0.25-\mathrm{L}$ & $75 \pm 25^{a}$ & $75 \pm 25^{a}$ & 25 & 25 & $44 \pm 11^{a}$ & $64 \pm 17^{a}$ & 33 & 36 \\
\hline S:G-0.5 & $92 \pm 14^{\mathrm{a}}$ & $92 \pm 14^{\mathrm{a}}$ & 8 & 8 & $45 \pm 10^{\mathrm{a}}$ & $81 \pm 7^{a b}$ & 32 & 19 \\
\hline $\mathrm{S}: \mathrm{G}-0.5-\mathrm{L}$ & $100 \pm 0^{a}$ & $100 \pm 0^{\mathrm{a}}$ & 0 & 0 & $47 \pm 1^{\mathrm{a}}$ & $69 \pm 10^{a}$ & 29 & 31 \\
\hline \multicolumn{9}{|c|}{ Persimmon black spot } \\
\hline Control & $68 \pm 3^{b}$ & $73 \pm 5^{b c}$ & - & - & $10.6 \pm 0.8^{a}$ & $21.9 \pm 1.9^{b}$ & - & - \\
\hline$S: G$ & $38 \pm 9^{a}$ & $45 \pm 12^{a}$ & 44 & 39 & $9.3 \pm 1.5^{\mathrm{a}}$ & $15.0 \pm 3.0^{\mathrm{a}}$ & 12 & 32.9 \\
\hline S:G-L & $70 \pm 10^{b}$ & $78 \pm 7^{b c}$ & 0 & 0 & $9.7 \pm 1.2^{\mathrm{a}}$ & $17.0 \pm 3.0^{a}$ & 9 & 20.8 \\
\hline S:G-0.25 & $42 \pm 7^{a}$ & $57 \pm 10 \mathrm{ab}$ & 39 & 23 & $10.8 \pm 1.1^{\mathrm{a}}$ & $15.5 \pm 1.4^{\mathrm{a}}$ & 0 & 29.4 \\
\hline S:G-0.25-L & $58 \pm 8^{a b}$ & $72 \pm 6^{b c}$ & 14 & 2 & $12.7 \pm 0.6^{a}$ & $18.8 \pm 1.9^{a b}$ & 0 & 14.2 \\
\hline S:G-0.5 & $42 \pm 7^{\mathrm{a}}$ & $53 \pm 7^{a b}$ & 39 & 27 & $11.4 \pm 0.3^{a}$ & $20.2 \pm 0.5^{\mathrm{ab}}$ & 0 & 8 \\
\hline S:G-0.5-L & $72 \pm 7^{b}$ & $82 \pm 8^{c}$ & 0 & 0 & $10.4 \pm 0.8^{a}$ & $17.6 \pm 0.6^{\mathrm{a}}$ & 2 & 20 \\
\hline
\end{tabular}

Starch-gellan coatings were more effective at reducing the incidence of black spot caused by A. alternata on persimmons (up to $40 \%$ reduction), although coatings containing lecithin were not effective, and the presence of EO was not observed to have any significant effect. Disease severity was not significantly reduced in coated persimmons. A multifactorial analysis (factors: the presence of lecithin and EO concentration) revealed two things: there was no significant influence of the EO, and the lecithin had a negative effect on the reduction of disease incidence and severity in infected fruit.

In general, applying a coating had a positive antifungal effect both on apples (a significant reduction in the severity of gray mold) and persimmons (a significant reduction in the incidence of black spot), but this antifungal effect was milder than that observed in in vitro work with EO incorporated into the same type of films. Similar behavior has recently been reported by da Rocha Neto et al. [15] for apples. They observed a complete inhibition of the in vitro germination of P. expansum by using melaleuca, palmarosa, and star anise EOs in vapor phase, but these treatments had only a minor effect on inoculated apples, regardless of the EO used. As previously reported [22,44], this indicates that the in vivo effectiveness of EOs cannot be anticipated by their antifungal activity in in vitro tests, and that interactions between EOs and fungal pathogens are modulated by the fruit host and the conditions in the infection court, often resulting in reduced disease control ability. An important difference in the potential effect of $\mathrm{EO}$ with respect to in vitro tests could be related with the degree of coating plasticization, which may affect the release of EO. In in vitro tests, films are directly applied on the wet culture medium, whereas coatings are applied on the dried fruit surface. This fact could limit the release of the active compounds from the polymer matrix, hindering their antifungal action. 
Likewise, EO compounds may also affect some physiological changes in the fruit, which could decrease the fruit's natural defenses against the fungal attack. The generally negative effect of lecithin could also be attributed to the lipid interactions with the fruit's waxy coatings, which could also weaken the natural resistance to disease, counteracting the induced coating protection. Other surfactant lipids, such as Tween 85, also seemed to exert a negative effect on the barrier capacity of the natural wax-coating assembly, as observed in apples. The gas exchange on the fruit surface could also play an important role in postharvest disease development, which could explain the generally positive effect of coatings at reducing fungal growth on infected fruit. Therefore, interactions of coatings and their components with the fruit surface always constitute a distinguishing factor to define the particular behavior of coated fruit [45], and in the case of coatings formulated with antifungal ingredients, these interactions can affect the in vivo disease control ability of the coating [46]. The results obtained in the present study with the addition of thyme EO to starch-based coatings were not anticipated. Numerous previous studies have shown that the formulation of antifungal films and coatings with EOs either provided disease control ability or increased that of the coating alone due to an important synergistic effect against various important postharvest pathogens, including B. cinerea and A. alternata $[12,47,48]$. However, this is not always the case, and other reports showed no significant benefit gained from the addition of EOs [49]. It seems that a wide variability in disease control efficacy can be observed, which is basically due to the numerous factors that can influence the antifungal properties of films and coatings. The following can be cited among the most important: nature of the composite matrix of the coating; type and concentration of the antifungal compound(s); species and strain of the target postharvest pathogen; species, cultivar, and physical and physiological condition of the fruit host; and postharvest environmental conditions [46]. Therefore, further studies would be required to analyze the influence of these factors.

\section{Conclusions}

Starch-gellan coatings containing or not emulsified or lecithin-encapsulated EO had a different effect on the postharvest parameters (weight loss, respiration rates and firmness changes) when applied on apples and persimmons, depending on the coating composition and type of fruit. None of the coating formulations reduced the weight loss in apples, although these prevented water loss in persimmons. In contrast, although the coating was not observed to have any significant effect on the respiration rates and respiration quotient of persimmons, the respiration rates and quotient in apples were promoted. Coatings did not affect the changes in fruit firmness in apples or persimmons; nevertheless, in the latter, these may be mainly associated with the ripening progress. Regarding fungal decay, coatings without lecithin reduced the incidence of black spot caused by A. alternata in persimmons, regardless of the thyme EO content. Likewise, these reduced the severity of gray mold caused by B. cinerea infection in apple. The addition of EO did not exert an antifungal effect in the fruit despite its proven antifungal action in previous in vitro tests. Therefore, the particular characteristics of the fruit and the interactions in the infection site (peel wounds) seriously affected the in vivo effectiveness of coatings of certain composition. No positive effect of lecithin was observed on the controlled postharvest parameters affecting fruit quality and physiological behavior in either apples or persimmons; EO did not exert additional antifungal action and seemed to exert a negative effect on some other fruit quality attributes. Then, starch-gellan coatings without lecithin or thyme EO demonstrated the potential to be used in persimmons in order to control weight loss and reduce the incidence of infections caused by A. alternata.

Author Contributions: Conceptualization, M.S., L.P., M.B.P.-G., and A.C.; methodology, L.P., M.B.P.-G., and A.C.; investigation, M.S.; writing-original draft preparation, M.S. and A.C.; writing—review and editing, M.S., L.P., M.B.P.-G. and A.C. 
Funding: This research was funded by the "Ministerio de Economía y Competitividad" (MINECO) of Spain through the projects AGL2016-76699-R and RTA2015-00037-C02. Mayra Sapper thanks the "Conselleria de Educación, Investigación, Cultura y Deporte de la Generalitat Valenciana" for the Santiago Grisolía grant GRISOLIA/2015/001.

Conflicts of Interest: The authors declare no conflict of interest.

\section{References}

1. Singh, D.; Sharma, R.R. Postharvest diseases of fruits and vegetables and their management. In Postharvest Disinfection of Fruits and Vegetables; Siddiqui, M.W., Ed.; Academic Press: London, UK, 2018; pp. 1-52. [CrossRef]

2. Sivakumar, D.; Bautista-Baños, S. A review on the use of essential oils for postharvest decay control and maintenance of fruit quality during storage. Crop Prot. 2014, 64, 27-37. [CrossRef]

3. Troncoso-Rojas, R.; Tiznado-Hernández, M.E. Alternaria alternata (black rot, black spot). In Postharvest Decay: Control Strategies; Bautista-Baños, S., Ed.; Academic Press: London, UK, 2014; pp. 147-187. [CrossRef]

4. Batta, Y.A. Postharvest biological control of apple gray mold by Trichoderma harzianum Rifai formulated in an invert emulsion. Crop Prot. 2004, 23, 19-26. [CrossRef]

5. Palou, L.; Montesinos-Herrero, C.; Tarazona, I.; Besada, C.; Taberner, V. Incidence and etiology of postharvest fungal diseases of persimmon (Diospyros Kaki Thunb. Cv. Rojo Brillante) in Spain. Plant Dis. 2015, 99, 1416-1425. [CrossRef] [PubMed]

6. Ma, L.; He, J.; Liu, H.; Zhou, H. The phenylpropanoid pathway affects apple fruit resistance to Botrytis cinerea. J. Phytopathol. 2018, 166, 206-215. [CrossRef]

7. Romanazzi, G.; Feliziani, E. Botrytis cinerea (gray mold). In Postharvest Decay: Control Strategies; Bautista-Baños, S., Ed.; Academic Press: London, UK, 2014; pp. 131-146. [CrossRef]

8. Prusky, D.; Eshel, D.; Kobiler, I.; Yakoby, N.; Beno-Moualem, D.; Ackerman, M.; Zuthji, Y.; Ben Arie, R. Postharvest chlorine treatments for the control of the persimmon black spot disease caused by Alternaria alternata. Postharvest Biol. Technol. 2001, 22, 271-277. [CrossRef]

9. Biton, E.; Kobiler, I.; Feygenberg, O.; Yaari, M.; Kaplunov, T.; Ackerman, M.; Friedman, H.; Prusky, D. The mechanism of differential susceptibility to alternaria black spot, caused by Alternaria alternata, of stem-and bottom-end tissues of persimmon fruit. Postharvest Biol. Technol. 2014, 94, 74-81. [CrossRef]

10. Olivas, G.; Barbosa-Cánovas, G. Edible films and coatings for fruits and vegetables. In Edible Films and Coatings for Food Applications; Embuscado, M.E., Huber, K.C., Eds.; Springer: New York, NY, USA, 2009; pp. 211-244. [CrossRef]

11. Maftoonazad, N.; Ramaswamy, H.S.; Marcotte, M. Shelf-life extension of peaches through sodium alginate and methyl cellulose edible coatings. Int. J. Food Sci. Technol. 2008, 43, 951-957. [CrossRef]

12. Fonseca, S.C.; Oliveira, F.A.R.; Brecht, J.K. Modelling respiration rate of fresh fruits and vegetables for modified atmosphere packages: A review. J. Food Eng. 2002, 52, 99-119. [CrossRef]

13. Morice, I.M.; Shorland, F.B. Composition of the surface waxes of apple fruits and changes during storage. J. Sci. Food Agric. 1973, 24, 1331-1339. [CrossRef]

14. Prusky, D.; Kobiler, I.; Akerman, M.; Miyara, I. Effect of acidic solutions and acidic prochloraz on the control of postharvest decay caused by Alternaria alternata in mango and persimmon fruit. Postharvest Biol. Technol. 2006, 42, 134-141. [CrossRef]

15. Da Rocha Neto, A.C.; Navarro, B.B.; Canton, L.; Maraschin, M.; Di Piero, R.M. Antifungal activity of palmarosa (Cymbopogon martinii), tea tree (Melaleuca alternifolia) and star anise (Illicium verum) essential oils against Penicillium expansum and their mechanisms of action. LWT-Food Sci. Technol. 2019, 105, 385-392. [CrossRef]

16. El Ouadi, Y.; Manssouri, M.; Bouyanzer, A.; Majidi, L.; Bendaif, H.; Elmsellem, H.; Shariati, M.A.; Melhaoui, A.; Hammouti, B. Essential oil composition and antifungal activity of Melissa officinalis originating from North-Est Morocco, against postharvest phytopathogenic fungi in apples. Microb. Pathog. 2017, 107, 321-326. [CrossRef] [PubMed]

17. Desjobert, J.M.; Cristofari, G.; Paolini, J.; Costa, J.; Majidi, L.; Znini, M. Essential oil composition and antifungal activity of Pulicaria mauritanica coss., against postharvest phytopathogenic fungi in apples. LWT-Food Sci. Technol. 2013, 54, 564-569. [CrossRef] 
18. Perdones, A.; Sánchez-González, L.; Chiralt, A.; Vargas, M. Effect of chitosan-lemon essential oil coatings on storage-keeping quality of strawberry. Postharvest Biol. Technol. 2012, 70, 32-41. [CrossRef]

19. Daniel, C.K.; Lennox, C.L.; Vries, F.A. In vivo application of garlic extracts in combination with clove oil to prevent postharvest decay caused by Botrytis cinerea, Penicillium expansum and Neofabraea alba on apples. Postharvest Biol. Technol. 2014, 99, 88-92. [CrossRef]

20. Munhuweyi, K.; Caleb, O.J.; Lennox, C.L.; van Reenen, A.J.; Opara, U.L. In vitro and in vivo antifungal activity of chitosan-essential oils against pomegranate fruit pathogens. Postharvest Biol. Technol. 2017, 129, 9-22. [CrossRef]

21. Bakkali, F.; Averbeck, S.; Averbeck, D.; Idaomar, M. Biological effects of essential oils-A review. Food Chem. Toxicol. 2008, 46, 446-475. [CrossRef]

22. Palou, L.; Ali, A.; Fallik, E.; Romanazzi, G. GRAS, plant-and animal-derived compounds as alternatives to conventional fungicides for the control of postharvest diseases of fresh horticultural produce. Postharvest Biol. Technol. 2016, 122, 41-52. [CrossRef]

23. Sánchez-González, L.; Vargas, M.; González-Martínez, C.; Chiralt, A.; Cháfer, M. Use of essential oils in bioactive edible coatings: A review. Food Eng. Rev. 2011, 3,1-16. [CrossRef]

24. Sapper, M.; Wilcaso, P.; Santamarina, M.P.; Roselló, J.; Chiralt, A. Antifungal and functional properties of starch-gellan films containing thyme (Thymus zygis) essential oil. Food Control. 2018, 92, 505-515. [CrossRef]

25. Plotto, A.; Roberts, D.D.; Roberts, R.G. Evaluation of plant essential oils as natural postharvest disease control of tomato (Lycopersicon esculentum). Acta Hortic. 2003, 628, 737-745. [CrossRef]

26. Cano, A.; Fortunati, E.; Cháfer, M.; Kenny, J.M.; Chiralt, A.; González-Martínez, C. Properties and ageing behaviour of pea starch films as affected by blend with poly(vinyl alcohol). Food Hydrocoll. 2015, 48, 84-93. [CrossRef]

27. Jiménez, A.; Fabra, M.J.; Talens, P.; Chiralt, A. Edible and biodegradable starch films: A review. Food Bioprocess Technol. 2012, 5, 2058-2076. [CrossRef]

28. Valencia-Sullca, C.; Jiménez, M.; Jiménez, A.; Atarés, L.; Vargas, M.; Chiralt, A. Influence of liposome encapsulated essential oils on properties of chitosan films. Polym. Int. 2016, 65, 979-987. [CrossRef]

29. Sapper, M.; Bonet, M.; Chiralt, A. Wettability of starch-gellan coatings on fruits, as affected by the incorporation of essential oil and/or surfactants. LWT-Food Sci. Technol. under review.

30. Kwok, D.Y.; Neumann, A.W. Contact angle measurement and contact angle interpretation. Adv. Colloid Interface Sci. 1999, 81, 167-249. [CrossRef]

31. Bai, J.; Baldwin, E.A.; Hagenmaier, R.H. Alternatives to shellac coatings provide comparable gloss, internal gas modification, and quality for "delicious" apple fruit. HortScience 2002, 37, 559-563. [CrossRef]

32. Marín, A.; Atarés, L.; Cháfer, M.; Chiralt, A. Properties of biopolymer dispersions and films used as carriers of the biocontrol agent Candida sake CPA-1. LWT-Food Sci. Technol. 2017, 79, 60-69. [CrossRef]

33. Castelló, M.L.; Fito, P.J.; Chiralt, A. Changes in respiration rate and physical properties of strawberries due to osmotic dehydration and storage. J. Food Eng. 2010, 97, 64-71. [CrossRef]

34. Saei, A.; Tustin, D.S.; Zamani, Z.; Talaie, A.; Hall, A.J. Cropping effects on the loss of apple fruit firmness during storage: the relationship between texture retention and fruit dry matter concentration. Sci. Hortic. 2011, 130, 256-265. [CrossRef]

35. Belding, R.; Blankenship, S.; Young, E.; Leidy, R. Composition and variability of epicuticular waxes in apple cultivars. J. Am. Soc. Hortic. Sci. 1998, 123, 348-356. [CrossRef]

36. Ju, Z.; Bramlage, W.J. Developmental changes of cuticular constituents and their association with ethylene during fruit ripening in "Delicious" apples. Postharvest Biol. Technol. 2001, 21, 257-263. [CrossRef]

37. Saberi, B.; Golding, J.B.; Marques, J.R.; Pristijono, P.; Chockchaisawasdee, S.; Scarlett, C.J.; Stathopoulos, C.E. Application of biocomposite edible coatings based on pea starch and guar gum on quality, storability and shelf life of 'Valencia' oranges. Postharvest Biol. Technol. 2018, 137, 9-20. [CrossRef]

38. Navarro-Tarazaga, M.L.; Sothornvit, R.; Pérez-Gago, M.B. Effect of plasticizer type and amount on hydroxypropyl methylcellulose-beeswax edible film properties and postharvest quality of coated plums (cv. Angeleno). J. Agric. Food Chem. 2008, 56, 9502-9509. [CrossRef] [PubMed]

39. Pastor, C.; Sanchez-Gonzalez, L.; Marcilla, A.; Chiralt, A.; Cháfer, M.; Gonzalez-Martinez, C. Quality and safety of table grapes coated with hydroxypropylmethylcellulose edible coatings containing propolis extract. Postharvest Biol. Technol. 2011, 60, 64-70. [CrossRef] 
40. Fagundes, C.; Palou, L.; Monteiro, A.R.; Pérez-Gago, M.B. Hydroxypropyl methylcellulose-beeswax edible coatings formulated with antifungal food additives to reduce Alternaria black spot and maintain postharvest quality of cold-stored cherry tomatoes. Sci. Hortic. (Amsterdam) 2015, 193, 249-257. [CrossRef]

41. Fagundes, C.; Carciofi, B.A.M.; Monteiro, A.R. Estimate of respiration rate and physicochemical changes of fresh-cut apples stored under different temperatures. Food Sci. Technol. 2013, 33, 60-67. [CrossRef]

42. Ribeiro, C.; Vicente, A.A.; Teixeira, J.A.; Miranda, C. Optimization of edible coating composition to retard strawberry fruit senescence. Postharvest Biol. Technol. 2007, 44, 63-70. [CrossRef]

43. Harker, F.R.; Feng, J.; Johnston, J.W.; Gamble, J.; Alavi, M.; Hall, M.; Chheang, S.L. Influence of postharvest water loss on apple quality: The use of a sensory panel to verify destructive and non-destructive instrumental measurements of texture. Postharvest Biol. Technol. 2019, 148, 32-37. [CrossRef]

44. Tripathi, P.; Dubey, N.K.; Banerji, R.; Chansouria, J.P.N. Evaluation of some essential oils as botanical fungitoxicants in management of post-harvest rotting of citrus fruits. World J. Microbiol. Biotechnol. 2004, 20, 317-321. [CrossRef]

45. Basiak, E.; Linke, M.; Debeaufort, F.; Lenart, A.; Geyer, M. Dynamic behaviour of starch-based coatings on fruit surfaces. Postharvest Biol. Technol. 2019, 147, 166-173. [CrossRef]

46. Valencia-Chamorro, S.A.; Palou, L.; del Río, M.A.; Pérez-Gago, M.B. Antimicrobial edible films and coatings for fresh and minimally processed fruits and vegetables: A review. Crit. Rev. Food Sci. Nutr. 2011, 51, 872-900. [CrossRef] [PubMed]

47. Grande-Tovar, C.D.; Chaves-Lopez, C.; Serio, A.; Rossi, C.; Paparella, A. Chitosan coatings enriched with essential oils: Effects on fungi involve in fruit decay and mechanisms of action. Trends Food Sci. Technol. 2018, 78, 61-71. [CrossRef]

48. Campos-Requena, V.H.; Pérez, M.A.; Sanfuentes, E.A.; Figueroa, N.E.; Figueroa, C.R.; Rivas, B.L. Thermoplastic starch/clay nanocomposites loaded with essential oil constituents as packaging for strawberries-In vivo antimicrobial synergy over Botrytis cinerea. Postharvest Biol. Technol. 2017, 129, 29-36. [CrossRef]

49. Shao, X.; Cao, B.; Xu, F.; Xie, S.; Yu, D.; Wang, H. Effect of postharvest application of chitosan combined with clove oil against citrus green mold. Postharvest Biol. Technol. 2015, 99, 37-43. [CrossRef]

(C) 2019 by the authors. Licensee MDPI, Basel, Switzerland. This article is an open access article distributed under the terms and conditions of the Creative Commons Attribution (CC BY) license (http://creativecommons.org/licenses/by/4.0/). 